\title{
Prevalence of Chronic Tonsillitis and Peculiarities of its Clinical Current in Residents of the Tyumen Region
}

\author{
Izvin AI* and Khatskelevich DM \\ Department of Otolaryngology, Tyumen Medical State University, Russia \\ *Corresponding author: AI Izvin, Department of Otolaryngology, Tyumen Medical State University, Tyumen, Russia
}

\begin{abstract}
The article presents the prevalence of chronic tonsillitis (CT) in children, adolescents and adults in the northern region of Russia (Tyumen region) over the past 4 years (2015-2018). It was shown that in all studied groups the incidence of chemotherapy is 3 times higher in children and 2 times higher in adolescents in the national districts of the region. The incidence among adults throughout the region varies in the same numbers. An analysis of 106 outpatient charts of patients with chemotherapy revealed that only $20.8 \%$ of patients had a history of previously experienced sore throats, more often patients were concerned about discharge from lacunar plugs with an unpleasant odor (64.2\%) and discomfort in the throat with prolonged subfebrile condition (83, 3 and 87.7 , respectively). In $21.7 \%$ of patients, a recurrent paratonsillar abscess was verified without a history of angina.
\end{abstract}

Keywords: Chronic tonsillitis; incidence; northern region of Russia

\section{Introduction}

WHO declared 2019 the year of tonsillar pathology, and this is no accident, because chronic tonsillitis (CT) and is currently a common disease, both among various population groups and their place of residence. Thus, the prevalence of chemotherapy according to various authors is from 0.8 to $45 \%$ [1-4]. In the harsh climate of Siberia, chronic diseases of the tonsils are found in $25-42 \%$ of the population $[5,6]$. In certain age groups in adults and children, this indicator reaches 230 and 190 cases per 1000 persons of the corresponding age. Thomson $\mathrm{C}$ et al. [7] revealed the highest incidence in the age group of 16-20 years, explaining this by the increased virulence of microorganisms and a decrease in the reactivity of the organism.

\section{Materials and Methods}

The incidence of chronic tonsillitis was studied among various population groups in the northern region of Russia: children (D), adolescents (P) and adults (B) over the past five years (2014 2018), living in the Tyumen region, the territory of which extends from of the Arctic Ocean to the border with Kazakhstan (Table 1).

Table 1: The incidence of chronic tonsillitis among various age groups of the Tyumen region.

\begin{tabular}{|c|c|c|c|c|c|c|c|c|c|c|c|c|c|c|c|}
\hline \multirow{2}{*}{ State } & \multicolumn{3}{|c|}{2014} & \multicolumn{3}{|c|}{2015} & \multicolumn{3}{|c|}{2016} & \multicolumn{3}{|c|}{2017} & \multicolumn{3}{|c|}{2018} \\
\hline & Ch. & Ad. & A & Ch. & Ad. & A & Ch. & Ad. & A & Ch. & Ad. & A & Ch. & Ad. & $\mathbf{A}$ \\
\hline \multirow{2}{*}{ Yamal } & $\underline{931}$ & $\underline{169}$ & $\underline{306}$ & $\underline{1000}$ & $\underline{155}$ & $\underline{310}$ & $\underline{2005}$ & $\underline{205}$ & $\underline{402}$ & $\underline{2240}$ & $\underline{280}$ & $\underline{480}$ & $\underline{503}$ & $\underline{296}$ & $\underline{443}$ \\
\hline & 2.1 & 0.32 & 1.6 & 2 & 0.3 & 1.6 & 4 & 0.4 & 0.6 & 4.2 & 0.5 & 0.7 & 0.9 & 0.6 & 0.8 \\
\hline \multirow{2}{*}{ KMAO } & $\underline{2910}$ & $\underline{307}$ & $\underline{620}$ & $\underline{2992}$ & $\underline{350}$ & $\underline{790}$ & $\underline{2854}$ & $\underline{350}$ & $\underline{1008}$ & $\underline{3100}$ & $\underline{408}$ & $\underline{1200}$ & $\underline{2946}$ & $\underline{768}$ & $\underline{1185}$ \\
\hline & 2.2 & 0.3 & 0.5 & 2.1 & 0.3 & 0.6 & 2.1 & 0.3 & 0.8 & 2.4 & 0.4 & 0.9 & 0.2 & 0.1 & 0.1 \\
\hline \multirow{2}{*}{ Tyumen } & $\underline{1461}$ & $\underline{182}$ & $\underline{623}$ & $\underline{1567}$ & $\underline{260}$ & $\underline{727}$ & $\underline{1488}$ & $\underline{189}$ & $\underline{768}$ & $\underline{1581}$ & $\underline{280}$ & $\underline{794}$ & $\underline{694}$ & $\underline{193}$ & $\underline{418}$ \\
\hline & 2.7 & 0.4 & 1.2 & 2.8 & 0.5 & 1.3 & 2.7 & 0.3 & 1.4 & 2.1 & 0.5 & 1.4 & 0.9 & 0.8 & 0.7 \\
\hline \multirow{2}{*}{ South of state } & $\underline{642}$ & $\underline{240}$ & $\underline{511}$ & $\underline{912}$ & $\underline{261}$ & $\underline{562}$ & $\underline{719}$ & $\underline{241}$ & $\underline{545}$ & $\underline{810}$ & $\underline{251}$ & $\underline{560}$ & $\underline{762}$ & $\underline{404}$ & $\underline{530}$ \\
\hline & 0.6 & 0.2 & 0.6 & 1.1 & 0.3 & 0.7 & 0.9 & 0.3 & 0.7 & 1 & 0.3 & 0.7 & 0.6 & 0.4 & 0.5 \\
\hline
\end{tabular}

Remark: Ch: Children; Ad: Adolescents; A: Aldults; KMAO: Khanty-Mansi Autonomous Okrug. 


\section{Results and Discussion}

The results (Table1) show that there is an increase in the incidence of chronic tonsillitis over the years both in all studied groups and throughout the region. However, the largest increase in the incidence is observed in the autonomous national districts (Yamal-Nenets Autonomous Okrug and Khanty-Mansi Autonomous Okrug), which, compared with the south of the region, is more than three times higher in children and two times in adolescents. The incidence among adults throughout the region varies in the same numbers. We are inclined to explain the high incidence of chronic tonsillitis among residents in the northern districts of the region due to the severe climatic conditions of the latter, the leading among which is cold. It is known that cooling reduces the body's resistance to infection and, ultimately, leads to inhibition of immunological reactivity. That is why, tonsils, being in essence their "first line of defense", are most often involved in the pathological process. At the same time, beginning in 2014, residents of the south of the region, in all age groups, also have a tendency to increase the number of patients with chronic tonsillitis, which is due, in our opinion, to the migration of part of the population from the northern districts to their permanent residence in the agricultural areas of the south of the region.

It should be noted that in recent decades, the clinical course of almost all diseases known to medicine has changed. The latter circumstance is especially significant for chronic tonsillitis as an infectious-allergic disease. To clarify the features of the clinical course of chronic tonsillitis in people living in extreme conditions of the North of Siberia, we analyzed case histories and outpatient records in 106 patients with chronic heart disease aged 17 years and older who came to the ENT clinic. The analysis showed that only $20.8 \%$ of patients had a previous history of angina. But much more often, patients with HT were worried about discharge from lacunar plugs with an unpleasant odor (64.2\%) and unpleasant sensations in the throat with prolonged subfebrile condition (83.3 and 87.7, respectively). Quite often (21.7\%), a recurrent paratonsillar abscess was verified without a history of angina, which is obviously due to the latent course of the so-called "non- angina" form of chemotherapy. The observed group of patients underwent, as a rule, conservative treatment of chemotherapy in the form of low-frequency ultrasound (NUZ-therapy) using the Tonsillor apparatus. As a local immunotherapy, the biologically active preparation Tonsilgon $\mathrm{N}$ of the German company Bionorisa was prescribed 25 drops once a day for 2 weeks, in the absence of the effect of conservative treatment, a bilateral tonsillectomy was performed.

\section{Conclusion}

The revealed features of the clinical course of chemotherapy are associated, in our opinion, primarily with changes in the environment - environmental degradation, which entails a change in the state of immunity, as well as the uncontrolled use of antibiotics, which leads to the emergence of mutable and more resistant strains of microorganisms. All this together leads to a change in the clinical picture of the disease.

\section{References}

1. Sodatov IB (1994) Guide to otorhinolaryngology. Medicine, Moscow, Russia, pp. 348-363.

2. Dergachev VS (2001) A differential approach to the treatment of chronic tonsillitis. XVI Congress of Otorhinolaryngologists of Russia. pp. 359365.

3. Izvin AI (2015) Chronic tonsillitis and paratonsillar abscess. RIC Adveks, Tyumen, Russia, pp. 184.

4. Portenko GM, Portenko EG, Shmatov GP (2016) Information technology in solving the problem of chronic tonsillitis. Tver Rn-ta (Eds.), center of Tver Gos Med at pp. 194.

5. Reports of the Department of Health of the Administration of the Tyumen Region for $2014-2018$

6. Rymsha MA, Sazonova IL, Podvolotsky VV (1998) The use of the nonspecific immunomodulator stimelis in the treatment of patients with ENT pathology. Actual issues of otorhinolaryngology: materials of a regional scientific and practical conference dedicated to the $60^{\text {th }}$ anniversary of the Department of Otorhinolaryngology, Novosibirsk Medical Institute, Novosibirsk, Russia, pp. 147-149.

7. Thomson C, Blake P (1996) The increasing incidence of hospital admission for acute tonsillitis: 5-year review of the Wellington experience. N Z Med J 109(1027): 298-299.

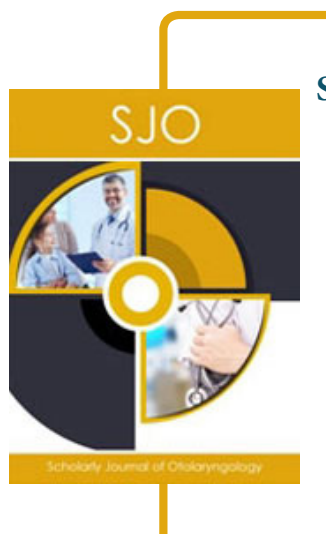

Scholarly Journal of Otolaryngology

\section{Assets of Publishing with us}

- Global archiving of articles

- Immediate, unrestricted online access

- Rigorous Peer Review Process

- Authors Retain Copyrights

- Unique DOI for all articles 